\title{
Reparasi dan Perhitungan Tahanan Kapal Nelayan di Daerah Nambangan Kelurahan Kedung Cowek - Surabaya
}

\author{
Erifive Pranatal $^{1}$, Gatot Basuki ${ }^{2}$, Norita Prasetya ${ }^{3}$ Maria Margareta ${ }^{4}$, Minto Basuki ${ }^{5}$ \\ 1, 2, 3, 4, 5 Jurusan Teknik Perkapalan, Fakultas Teknologi Mineral dan Kelautan, Institut Teknologi Adhi \\ Tama Surabaya - Jalan Arief Rahman Hakim No. 100, Surabaya \\ *e-mail corresponding author : erifive@itats.ac.id. Hp. 085275410631
}

\begin{abstract}
ABSTRAK
Kondisi lambung kapal kayu yang rusak dan ditumbuhi biota laut (fouling) berdampak negatif pada umur pakai kapal dan juga menambah tahanan kapal sehingga meningkatkan konsumsi bahan bakar. Oleh karena itu kapal harus diperbaiki secara berkala. Permasalah yang diselesaikan adalah bagaimana reparasi kapal kayu seperti penggantian papan kayu, pembersihan lambung, pengecatan dan juga analisa tahanan kapal kayu. Sehingga tujuan penulisan ini adalah melakukan reparasi kapal kayu dan juga analisa tahanan kapal. Sendangkan metode kegiatan yang digunakan adalah pelatihan yang diikuti demonstrasi dan juga simulasi ipteks yang menjelaskan tahanan kapal dengan bantuan software Maxsurf. Reparasi kapal ini terdiri dari penggantian papan lunas dan sisi kapal, pembersihan lambung, pendempulan dan pengecatan. Selanjutnya dilakukan pengukuran kapal untuk mendapatkan ukuran utama dan pembuatan gambar rencana garis dan model kapal 3D. Pada perhitungan tahanan kapal dengan menggunakan motor penggerak Honda GX 160 dengan daya 5,5 hp akan menghasilkan kecepatan 6,325 knot.
\end{abstract}

Kata kunci : reparasi; rencana garis; kapal kayu; tahanan kapal

\section{ABSTRACT}

Wooden hulls have been damaged and overgrown by fouling have negative impact on the service life and also increase the resistance of ship thereby increasing fuel consumption. Therefore the ship have to repaired regularly. The problem discussed is how to repair wooden ships such as replacing plank, cleaning hull and coating; and hull analysis to determine resistance of ship. Therefore the object of this paper is to repair wooden ships and resistance. The method used is training that is followed by demonstration and also science and technology simulation that explains the form hull and resistance of the ship with use of software Maxsurf. The ship's repairs consist of replacement plank on the keel, and the side; clean the hull, putty and coating. The ship is measured and the main dimension is obtained and then makes line plans and 3D ship models. The calculation of the ship's resistance shows that ship use main engine Honda GX 160 with $5.5 \mathrm{hp}$ will produce 6.325 knot.

Keywords : reparation; lines plan; wooden ship; resistance of ship

Cara Mengutip : Pranatal E., Basuki, G., Prasetya, N., Margareta, M., Basuki, M., (2020). Reparasi dan Perhitungan Tahanan Kapal Nelayan di Daerah Nambangan Kelurahan Kedung Cowek - Surabaya.

JAST : Jurnal Aplikasi Sains dan Teknologi, 4 (1), 1-8. doi:http://dx.doi.org/10.33366/jast.v4i1.1456 


\section{PENDAHULUAN}

Kapal memerlukan pemeliharaan dan reparasi yang rutin. Reparasi kapal dilakukan satu tahun sekali disebut juga dengan reparasi tahunan, dan reparasi pada saat kondisi kapal mengalami kerusakan. Reparasi berfungsi untuk menjaga kondisi kapal agar tetap mampu beroperasi dengan baik atau laik laut. Pekerjaan reparasi kapal kayu berupa penggantian papan kayu yang telah rusak, proses pembersihan lambung dari biotabiota laut, dan pengecatan [1]. Oleh sebab itu Jurusan Teknik Perkapalan ITATS melakukan Kegiatan pengabdian kepada masyarakat yang berlokasi di daerah Nambangan Kelurahan Kedung Cowek Surabaya. Nelayan tradisional tersebut memiliki kapal dengan panjang 7 meter dan terbuat dari kayu jati.

Fokus kegiatan ini adalah melakukan reparasi dan pengecatan kapal. Selanjutnya dilakuan menggambar rencana garis dan perhitungan tahanan kapal tersebut.

Tujuan utama kegiatan PKM adalah: melakukan reparasi (penggantian kapal kayu, pembersihan lambung dan pengecatan) dan penggambaran rencana garis lambung dan analisa tahanan kapal kayu nelayan di daerah Nambangan Kelurahan Kedung Cowek- Surabaya.

\section{METODE KEGIATAN}

Ada dua metode yang digunakan pada kegiatan pengabdian masyarakat ini, yaitu a. pelatihan diikuti demostrasi kegiatan yaitu dilakukan pemaparan langkah-langkah yang diperlukan untuk reparasi dan pengecatan lambung kapal, b. simulasi Iptek, yakni menjelaskan tentang analisa bentuk lambung kapal ke dalam rencana garis, perhitungan tahanan kapal dengan menggunakan software Maxsurf. Selanjuntya dilakukan analisa pemilihan motor penggerak kapal.

\section{KARYA UTAMA}

Karya utama terdiri dari tiga bagian yaitu penjelasan proses reparasi kepada nelayan yang diikuti pengerjaannya, dan penggambaran rencana garis kapal, dan perhitungan tahanan termasuk juga pemilihan motor induk kapal nelayan.

\subsection{Proses Reparasi}

Proses reparasi kapal kayu nelayan dilakukan sebagai berikut:

- Penarikan kapal kayu ke area pantai. Hal ini dilakukan dengan sangat tradisional, yakni dengan tenaga manusia. Balok-balok kayu disusun berjajaran di pantai, dimana kapal akan ditarik di atas balok tersebut. Setelah kapal diangkat ke darat kemudian kapal diikat agar tidak mengalamai slip ke pantai. Proses penarikan kapal ke darat dan setelah ditarik dapat dilihat pada gambar 1 berikut ini:

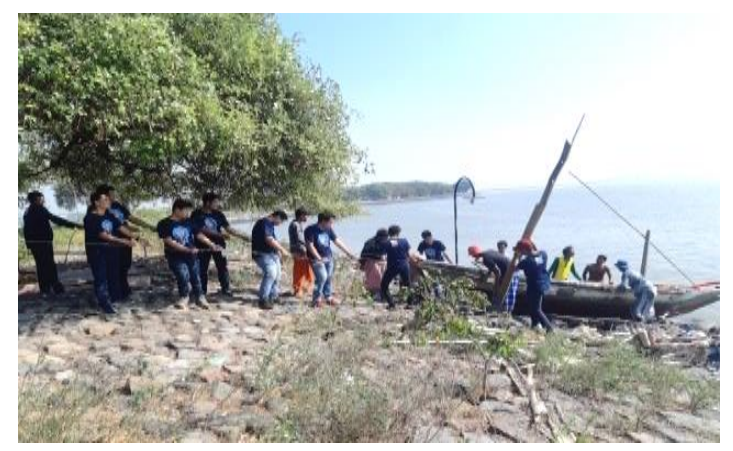

Gambar 1a. Proses penarikan kapal 


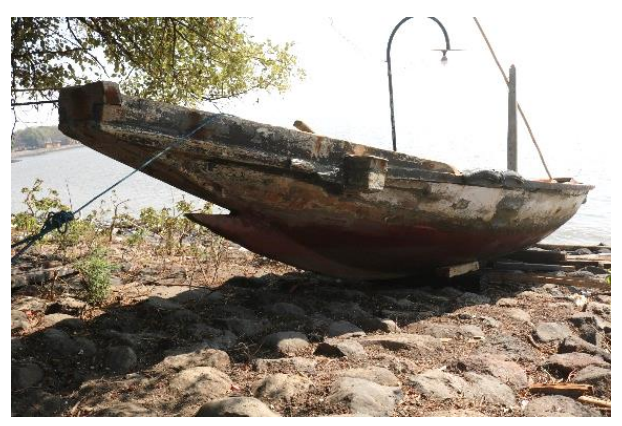

Gambar 1b. Kapal yang telah ditarik.

o Pembersihan lambung kapal. Lambung kapal dibersihkan dari fouling, lumut dan cat lama. Pengerjakan ini dilakukan dengan kapi cat, dan juga gerinda. Biofouling yang menempel pada lambung kapal dapat dilihat pada gambar 1 .

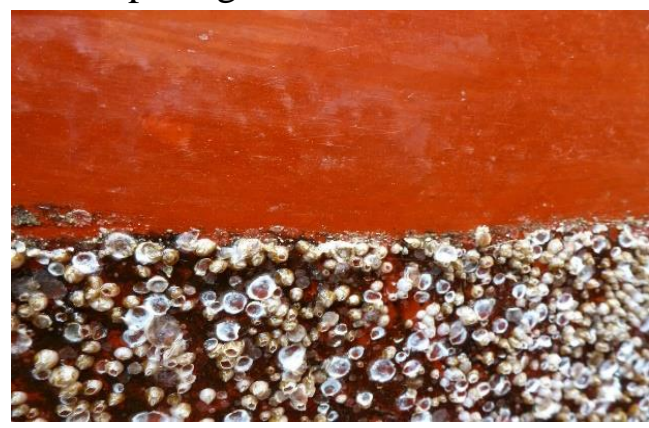

Gambar 2. Biofouling pada lambung

Tetapi sebelum pekerjaan tersebut nelayan setempat biasa melakukan pembakaran beberapa detik pada lambung kapal agar kayu semakin kering yang berguna untuk keawetan kayu. Kegiatan ini dapat dilihat pada gambar 3 berikut:

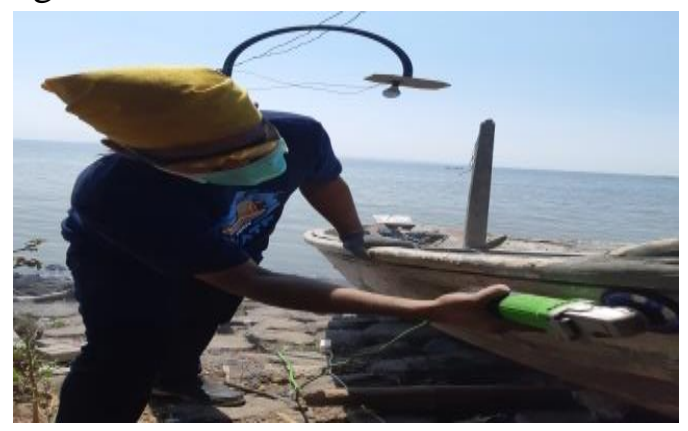

Gambar 3. Pembersihan labung kapal
- Pemakalan dan pergantian papan lambung kapal. Proses pemakalan adalah proses untuk menjaga kekedapan antar papan sehingga air tidak masuk ke dalam lambung. Bahan dempul yang digunakan oleh nelayan setempat adalah campuran semen, lem rajawali, dan serbuk kayu. Selanjutnya apabila kayu sudah tidak layak lagi untuk di dempul maka akan dilakukan pergantian papan lambung kapal. Sebelum ke proses selanjutnya yaitu pengecatan, lambung dibersihan dengan air tawar dan di keringkan dengan kain majun. Proses pemakalan dapat dilihat pada gambar 4

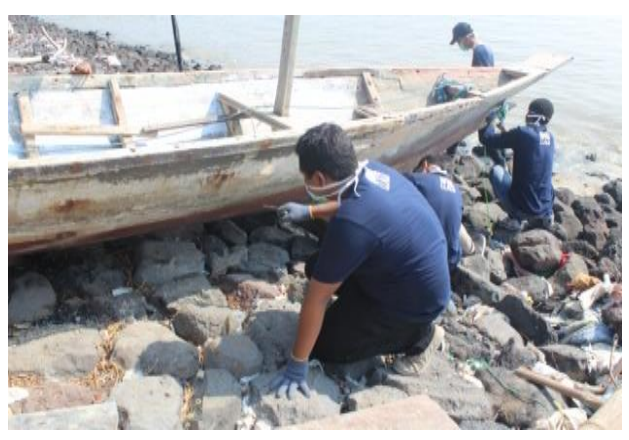

Gambar 4. Pemakalan dan dempul lambung kapal

- Proses Pengecatan. Pengecatan kapal dilakukan terlebih dahulu pada lambung di bawah garis air atau yang tercelup ke dalam air. Bagian kapal ini memerlukan perhatian khusus dikarenakan langsung bersentukan dengan air laut sehingga tumbuh fouling. Oleh sebab itu cat yang digunakan juga berbeda dari biasanya, yaitu lapisan pertama menggunakan cat dasar, lapisan kedua menggunakan cat tengah atau medium, dan lapisan terakhir menggunakan cat anti fouling. Cat dasar berfungsi untuk membuat kayu kedap air sehingga kayu tetap 
awet. Cat tengah berfungsi untuk menjaga ketebalan cat dan kekedapan papan, dan cat anti-fouling berfungsi untuk mencegah fouling (binatang atau tumbuhan micro) menempel pada lambung kapal. Cat ini memiliki zat tertentu yang dapat membuat fouling susah menempel.

Untuk bagian kapal di atas garis air menggunakan cat dasar dan cat akhir. Proses pengecatan dapat dilihat pada gambar 5.

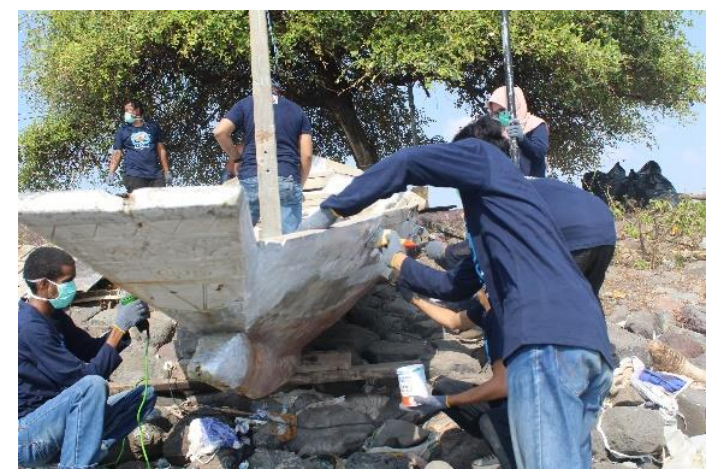

Gambar 5. Proses pengecatan

- Proses penurunan kapal. Setelah cat kering maka selanjutnya dilakukan proses penurunan kapal ke laut, gambar 6. Seperti proses penarikan kapal ke daerah pantai, proses ini juga dilakukan dengan cara tradisonal yaitu pengangkatan kapal dilakukan dengan tanaga manusia.

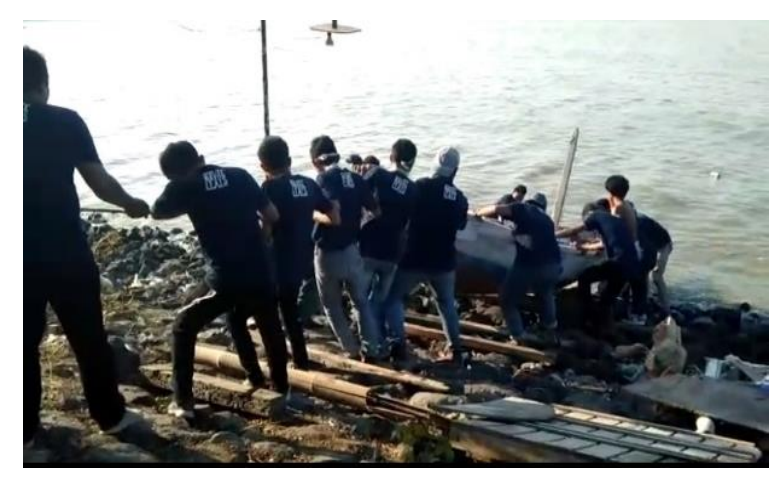

Gambar 6. Penurunan kapal ke laut

\subsection{Pembuatan Rencana Garis Kapal}

Rencana Garis (lines plan) adalah gambar desain kapal yang memperlihatkan bentuk lambung kapal dalam 2 dimensi yang dilihat pada tampak depan (sheer plan), samping ( body plan) dan atas (half breadth plan). Gambar ini merupakan gambar dasar untuk melakukan analisa terhadap lambung kapal. Untuk pembuatannya pertama dilakukan pengukuran pada kapal yang dapat dilihat pada gambar 7:

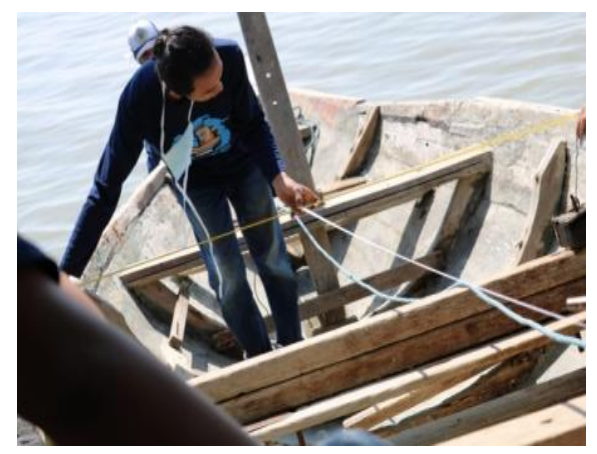

Gambar 7. Pengukuran kapal untuk memperoleh ukuran pokok

Ukuran pokok kapal yang dapat dilihat pada tabel 1:

Tabel 1. Ukuran Pokok Kapal Nelayan

\begin{tabular}{clc}
\hline No & \multicolumn{1}{c}{ Item } & Nilai $(\mathrm{m})$ \\
\hline LOA & Length Over & 7 \\
& All/panjang keseluruhan & \\
& kapal & \\
B & Breadth/Lebar kapal & 2 \\
H & Heigth/Tinggi kapal & 0,8 \\
T & Draft/Tinggi Sarat & 0.45 \\
\hline
\end{tabular}

Ukuran pokok digunakan untuk membuat model kapal dengan bantuan software Maxsurf Modeler [2]. Hasil penggambaran model 3D kapal dan gambar rencana garis dapat dilihat pada gambar 8 dan 9: 


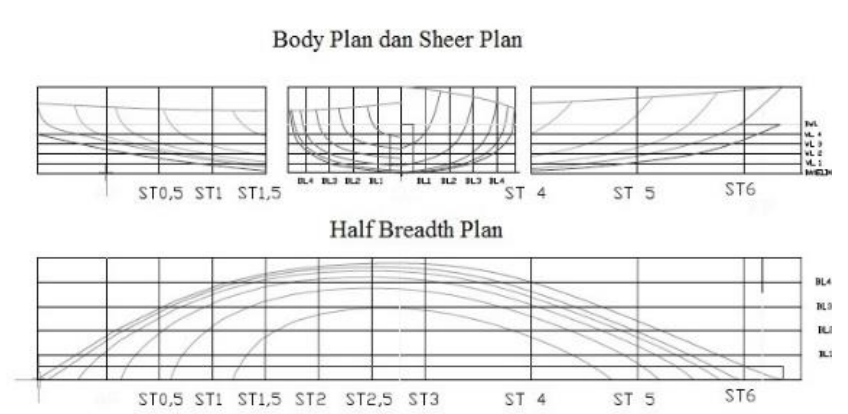

Gambar 8. Rencana Garis Kapal

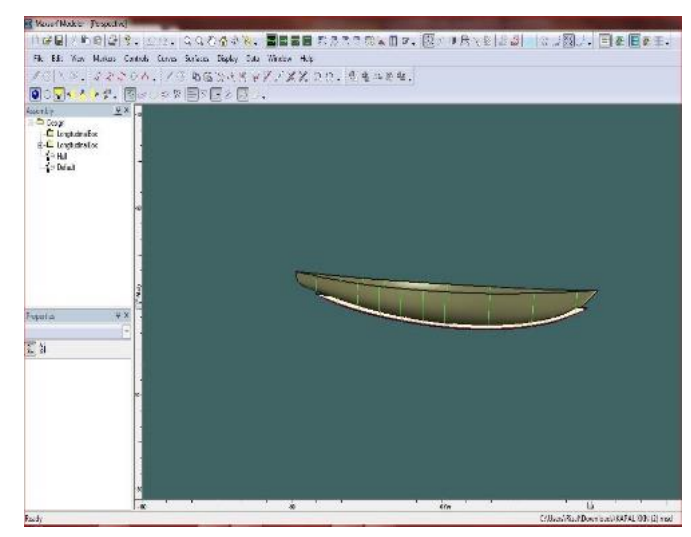

Gambar 9. Tampilan 3D software Maxsurf Modeler.

Setelah lines plan kapal telah diperoleh, maka selanjutnya pembuatan table offset. Table offset tersebut menunjukkan jarak dalam meter antara sisi kapal dengan centerline kapal pada masing-masing water line. Table offset dapat dilihat pada tabel 2 berikut:

Tabel 2. Table Offset of Waterline

\begin{tabular}{clllll}
\hline & WL1 & WL2 & WL3 & WL4 & WL5 \\
\hline AP & & & & & \\
ST1 & & & 0.325 & 0.505 & 0.564 \\
ST1.5 & & 0.393 & 0.649 & 0.743 & 0.784 \\
ST2 & 0.284 & 0.683 & 0.829 & 0.897 & 0.932 \\
ST2.5 & 0.568 & 0.806 & 0.919 & 0.978 & 1.011 \\
ST3 & 0.655 & 0.847 & 0.948 & 1.007 & 1.041 \\
ST4 & 0.582 & 0.76 & 0.864 & 0.931 & 0.979 \\
ST5 & 0.239 & 0.454 & 0.567 & 0.638 & 0.69 \\
ST6 & & & & & 0.04 \\
& & & & & \\
\hline
\end{tabular}

\subsection{Tahanan kapal.}

Tahanan kapal pada suatu kecepatan adalah gaya fluida yang bekerja pada kapal demikian rupa sehingga melawan gerakan kapal tersebut [2]. Perhitungan tahanan kapal dilakukan dengan bantuan software Maxsurf Resistance. Metode yang digunakan adalah Van Oortmerssen, Delft I,II dan Delft III sail dengan keceptan 0-8 knot dengan kondisi air tenang dan permukaan lambung mulus. Untuk perhitungan tahanan vs kecepatan dapat dilihat pada tabel 3 berikut ini:

Tabel 3. Tahanan Kapal vs Kecepatan

\begin{tabular}{llll}
\hline $\begin{array}{l}\text { Vs } \\
(\mathrm{knot})\end{array}$ & $\begin{array}{l}\text { Van } \\
\text { Oormerssen } \\
(\mathrm{kN})\end{array}$ & $\begin{array}{l}\text { Delft } \\
\text { I,II } \\
(\mathrm{kN})\end{array}$ & $\begin{array}{l}\text { Delft } \\
\text { III } \\
(\mathrm{kN})\end{array}$ \\
\hline 1 & & & 0 \\
2 & & & 0 \\
3 & 0.1 & 0.1 & 0.1 \\
4 & 0.1 & 0.1 & 0.1 \\
5 & 0.2 & 0.3 & 0.2 \\
6 & 0.5 & 0.6 & 0.6 \\
7 & 1.5 & 1.7 & 1.7 \\
8 & 2.3 & 2.9 & 2.6 \\
\hline
\end{tabular}

Motor yang biasa digunakan nelayan adalah motor tempel yang telah dimodifikasi dengan batang poros untuk menghubungkan motor dengan balingbaling. Motor tersebut memiliki daya 5,5 hp dan 6,5 hp dengan merek Honda GX 160 [4]. Hasil perhitungan daya mesin dapat dilihat pada tabel 4 berikut:

Tabel 4. Daya Kapal vs Kecepatan

\begin{tabular}{llll}
\hline $\begin{array}{l}\text { Vs } \\
\text { (knot) }\end{array}$ & $\begin{array}{l}\text { Van } \\
\text { Oormerssen } \\
\text { (hp) }\end{array}$ & $\begin{array}{l}\text { Delft } \\
\text { I,II } \\
\text { (hp) }\end{array}$ & $\begin{array}{l}\text { Delft } \\
\text { III } \\
\text { (hp) }\end{array}$ \\
\hline 1 & 0.007 & 0.007 & 0.003 \\
2 & 0.051 & 0.049 & 0.049 \\
3 & 0.206 & 0.188 & 0.188 \\
4 & 0.508 & 0.515 & 0.514 \\
5 & 1.212 & 1.252 & 1.203 \\
6 & 3.11 & 3.673 & 3.672 \\
7 & 10.467 & 11.714 & 11.741 \\
8 & 18.22 & 23.057 & 20.846 \\
\hline
\end{tabular}


Daya pada tabel 4 dihasilkan dengan efisiensi daya $70 \%$ dengan kata lain, sebanyak $30 \%$ daya yang hilang sepanjang transmiki ke propeller.

Berdasarkan tabel 4 di atas, apabila motor penggerak yang digunakan 5,5 hp maka dengan menggunakan interpolasi liner kecepatan kapal yang dihasilkan adalah 6,325 knot (Van Oormerssen), 6,227 knot (Delft I,II) dan 6,226 knot (Delft III). Kecepatan kapal ini berkurang apabila permukaan lambung kapal di bawah garis air ditumbui oleh biota laut atau fouling dengan daya sama yang dikeluarkanoleh mesin yaitu 5,5 hp. Selain itu kecepatan kapal menggunakan mesin tempel juga dipengaruhi oleh panjang poros balingbaling, sudut kemiringan poros terhadap permukaan air dan spesifikasi dari balingbaling.

\section{ULASAN KARYA}

Keunggulan pengabdian kepada masyarakat ini yaitu penggunaan teknologi yaitu software perkapalan untuk menggambarkan tahanan kapal. Dari perhitungan tahanan kapal tersebut kita dapat menegetahui kecepatan kapal pada daya yang tertera pada motor penggerak. Nelayan memilik motor penggerak Honda GX 160 yang daya 5,5 dan 6,5 hp. Jika daya motor 5,5 hp maka kecepatan kapal yang dihasilkan sekitar 6 knot atau sekitar 3,08667 m/s atau 11,112 $\mathrm{km} / \mathrm{jam}$. Kecepatan ini akan turun secara berlahan bila fouling menempel pada lambung kapal.

Sedangkan kelemahannya adalah reparasi kapal yang digunakan masih sangat tradisional khususnya pada proses menaikkan kapal ke darat masih menggunakan tenaga manusia atau otot. Oleh sebab itu rencana kegiatan pengabdian selanjutnya berupa desain dan pembangunan dock kapal untuk nelayan di daerah Nambangan. Apabila ini bisa terlaksana akan sangat membantu masyarakat nelayan. Selain itu, proses coating yang dipaparkan pada bagian sebelumnya mungkin memberatkan nelayan terutama dari sisi ekonomi. Sehingga mereka tetap menggunakan cara lama, yaitu hanya menggunakan cat anti-fouling pada lambung di bawah garis air dan cat Avian di bagian atas garis air.

\section{DAMPAK DAN MANFAAT KEGIATAN}

Kegiatan PKM ini memberikan gambaran yang baru kepada para nelayan tentang tujuan reparasi kapal yang bisa mereka lakukan. Yaitu reparasi lambung kapal mampu mengurangi konsumsi bahan bakar setiap harinya. Hal itu terjadi karena lambung kapal yang mulus tanpa biota laut atau fouling akan mengurangi gaya gesek antara fluida dalam hal ini air laut dengan lambung kapal. Pada penelitian A. K. Yusim [5] menjelaskan pertumbukan fouling selama satu tahun pada lambung kapal akan meningkatkan tahanan gesek sebesar $41 \%$ dibandingkan dengan lambung kapal tanpa fouling dan telah dicat mulus. Hal ini didukung juga oleh penelitian Baital, M. S., \& Utama, I. K. A. P [6], dengan metode numerik, menyatakan bahwa pertumbuhan fouling pada lambung dalam satu tahun akan meningkatkan tahanan kapal sebesar 37\% dan meningkat menjadi $80 \%$ dalam dua tahun.

Selain itu kegiatan ini juga memberikan pemaparan tentang coating 
atau pelapisan pada kapal. Sebelumnya pengecatan yang dilakukan oleh nelayan masih jauh standar pengecatan. Mereka mencat lambung kapal pada bagian bawah air hanya menggunakan cat antifouling. Sendangkan lambung di atas garis air menggunakan cat jenis Avian jenis cat akhir untuk material kayu. Sehingga kegiatan ini memaparkan bagaimana seharusnya melakukan pelapisan yang baik untuk kapal dengan material kayu. Pada bagian bawah garis air, jenis cat yang digunakan adalah cat dasar, cat tengah dan cat anti-fouling. Sendangkan untuk cat di atas garis air, cat dasar dan cat akhir. Tetapi nelayan masih tidak melakukan cara ini. Mereka memberikan alasan ekonomi untuk membeli macam-macam cat. Padalah jika cara ini lakukan, frekuensi untuk naik dok reparasi akan berkurang karena lambung menjadi awet dari fouling. Jadi dampak yang terutama dalam kegiatan ini adalah pemahaman dan wawasan nelayan tentang reparasi dibaharui, sehingga mereka memberi perhatian lebih untuk reparasi kapal terutama pembersihan lambung kapal dan pengecatan.

Manfaat kegitan ini juga terjadi pertukaran pengetahuan tentang reparasi kapal kayu antara nelayan dan juga pihak akademisi. Yaitu ada hal yang tidak diperoleh di akademik tetapi diterapkan dilingkungan nelayan. Seperti bagaimana nelayan untuk mendempul lambung kapal agar kuat dan tahan lama yaitu menggunakan campuran lem kertas rajawali dan semen. Manfaat lainnya yang dirasakan nelayan adalah bantuan yang diberikan seperti jaring ikan, alatalat reparasi dan juga bantuan tali asih.

\section{KESIMPULAN}

Reparasi kapal kayu yang telah dilakukan antara lain penggantian kayu pada lunas dan sisi kapal. Selanjutnya dilakukan pembersihan lambung kapal, pendempulan dan pengecatan kapal. Proses pemindahan kapal dari laut ke darat atau sebaliknya masih menggunakan cara tradisional, sehingga perlu dibangun sarana dan prasarana untuk menunjang hal tersebut.

Desain kapal nelayan tersebut memiliki panjang 7 meter dari ujung linggi haluan sampai ujung linggi buritan. Kapal tersebut memiliki lunas balok yang menonjol yang menjadi ciri khas dari perahu kayu tersebut. Sendangkan Tahanan kapal berturut-turut pada kecepatan 5, 6 dan 7 knot sebesar 0,2 kN, $0.5 \mathrm{kN}$ dan 1,5 serta daya yang dihasilkan untuk mencapai kecepatan tersebut adalah 1,212 hp, 3,11 hp dan 10,467 hp. Ditarik kesimpulan untuk menaikkan kecepatan dari 6 knot ke 7 knot memerlukan kurang daya 3 kali lipat. Oleh karena itu motor penggerak yang dipertimbangankan untuk digunakan berkisar 3,11 hp sampai $6 \mathrm{hp}$ sehingga dipilih Honda GX 160 dengan daya 5,5 hp dan menghasilkan kecepatan 6,325 knot.

\section{DAFTAR PUSTAKA}

[1] Wahyono, A. (2011) Kapal perikanan: membangun kapal kayu. Balai Besar Pengembangan Penangkapan Ikan, Direktorat Jenderal Perikanan Tangkap, Kementerian Kelautan dan Perikanan, 2011. 
[2] Bentley Systems. (2013). "Maxsuft Modeler Windows Version 20 User Manual". Maxsurf Modeler Program \& User Manual Bentley System, Incorporated.

[3] Harvald, S. (1983). Resistance and propulsion of ships. Ocean engineering. Wiley, 1983.

[4] Kalmanun, Anthon Daud (2012). "Kajian Teknis Kecepatan Kapal Jukung di UR Pulau Maluku Tenggara”. M.T tesis., IPB, 2012.

[5] Yusim, A. K., \& Utama, I. K. A. P. (2017). "An Investigation into the Drag Increase on Roughen Surface due to Marine Fouling Growth" IPTEK The Journal for Technology and Science 28(3).

[6] Baital, M. S., \& Utama, I. K. A. P. (2017). CFD Analysis into the Drag Estimation of Smooth and Roughened Surface Due to Marine Biofouling. IPTEK The Journal for Technology and Science, 28(3). 